\title{
Alterations in Cultured Fibroblasts of Sibs with an Infantile Form of a Free (Unbound) Sialic Acid Storage Disorder
}

\author{
GEORGE H. THOMAS, ${ }^{(25)}$ JANE SCOCCA, JACQUES LIBERT, ESTER VAMOS, CAROL S. MILLER, \\ AND LINDA W. REYNOLDS \\ The John F. Kennedy Institute, Baltimore, Maryland [G.H.T., J.S., C.S.M., L.W.R.]; Department of Pediatrics and \\ Medicine, The Johns Hopkins University, School of Medicine, Baltimore, Maryland [G.H.T.]; Department of \\ Ophthalmology, Hospital Saint Pierre, Université Libre de Bruxelles, Brussels, Belgium [J.L.]; and Department of \\ Pediatrics, Hospital Saint-Pierre, Université Libre de Bruxelles, Brussels, Belgium [E.V.]
}

\begin{abstract}
Summary
Cultured fibroblasts from two sibs with generalized hypertonia, hepatosplenomegaly, and psychomotor retardation within the first year of life were found to have unusual morphologic features. When examined by phase microscopy, the unstained and unfixed cells contained a large number of vacuolated structures whose gross appearance resembled that of a honeycomb in the cell cytoplasm. Electron microscopy studies, following fixation, showed the "honeycombing" to be the result of numerous, closely packed, cytoplasmic, membrane-bound vacuoles. In some of these structures the remains of fibrillogranular material could be detected.

Biochemical analysis of crude sonicates of these cells revealed increased levels $(4-7 \times N)$ of an acid soluble component that reacted with thiobarbituric acid. Analysis of trimethylsilyl derivatives of this material by gas liquid chromatography and mass spectrometry showed it to be indistinguishable from sialic acid $(N$ acetylneuraminic acid).

Quantitation of this material from the cells of one of the sibs after isolation on a Dowex column yielded 39.8 nmoles of free (unbound) sialic acid per mg protein whereas normal fibroblasts had 1-2 nmoles per mg. Bound sialic acid levels were at the upper limits of normal (24.8 versus 11-23 nmoles per $\mathrm{mg}$ protein). The concentration of cytidine monophosphate-sialic acid was normal.

After incubation of the patient's fibroblasts with $\left[{ }^{3} \mathrm{H}\right]-N$-acetylmannosamine for $72 \mathrm{~h}$, there was a 7 -fold increase (compared to normal fibroblasts) in the amount of radioactivity in free sialic acid present in the acid soluble fraction. The amount of labeled, bound sialic acid in the acid-insoluble pool, however, was the same in both patient and control fibroblasts.
\end{abstract}

\section{Abbreviations}

CMP, cytidine monophosphate

NANA, $N$-acetyl-neuraminic acid

PBS, phosphate buffered saline

TCA, trichloracetic acid

UDP, uridine diphosphate

Over the past few years several clinical forms of sialidosis have been described (14). Common to each of these related disorders has been an increased accumulation and/or excretion of sialic acid ( $N$-acetylneuraminic acid) covalently linked to a variety of oligosaccharides and/or glycoproteins. Additionally, it has been demonstrated that these alterations are associated with, and presumptively the result of, a deficiency of a lysosomal sialidase (neuraminidase) $(4,20,22)$.

We now describe the morphologic and biochemical features of fibroblasts cultured from two infants (sibs) who suffer not from a storage of "bound" sialic acid but, rather, from an increased accumulation and excretion of free sialic acid. In contrast to the sialidosis patients, these individuals have normal to above normal levels of sialidase. The clinical and/or biochemical findings in these patients clearly indicate that they suffer from a disorder distinct from either Salla disease $(3,17)$ or sialuria $(15)$, both of which are also characterized by an increased accumulation and/ or excretion of unbound sialic acid. These sibs, however, do appear to have certain features in common with patients recently described by Hancock et al. (5) and by Stevenson et al. (18).

\section{MATERIALS AND METHODS}

Cultured fibroblasts were established from skin biopsies of the patients and controls as previously described $(13,19)$. For biochemical studies, cells from two confluent cultures $\left(75 \mathrm{~cm}^{2}\right.$ tissue culture flasks) containing approximately $2 \mathrm{mg}$ protein were harvested with trypsin 7 days after subculture, pooled and washed three times in phosphate buffered saline with centrifugation after each wash step. The washed cells were resuspended in $2.0 \mathrm{ml}$ of deionized water and ruptured by ultrasonication (three 10 -sec treatments with intervals for cooling in ice water). Free sialic acid levels in 0.1-ml samples of the sonicates were measured by the thiobarbituric acid method as described by Aminoff (2) and modified by Uchida et al. (24). CMP-sialic acid was measured after destruction of free sialic acid with sodium borohydride according to the method of Kean and Roseman (10).

Where indicated, the free sialic acid was separated from crude cell sonicates before quantitation and/or preparation of derivatives for gas liquid chromatography-mass spectrometry. For these studies the crude sonicates were treated with perchloric acid (final concentration of $3.5 \%$ ), allowed to stand $10 \mathrm{~min}$, centrifuged ( 7700 $\times g$ for $10 \mathrm{~min}$ ) and the supernatants removed and saved for analysis. Precipitates were washed twice with $0.2 \mathrm{ml}$ of $\mathrm{H}_{2} \mathrm{O}$ and the washes were added to the supernatants. Supernatants were neutralized with $\mathrm{KOH}$, centrifuged to remove potassium perchlorate, and applied to $0.5 \times 5 \mathrm{~cm}$ columns of Dowex $1 \times 8$ acetate (100-200 mesh). Two $0.5-\mathrm{ml}$ water washes of the sample tube were added to the column. The columns were then eluted with $10 \%$ acetic acid (11). The first $5 \mathrm{ml}$ of the column effluent was discarded; the next $12.5 \mathrm{ml}$ was collected, evaporated to dryness under reduced pressure on a rotary evaporator and dissolved in $1.0 \mathrm{ml}$ of water for quantitation with thiobarbituric acid and/or preparation of derivatives. Methylesters were prepared using methanol and Dowex $50 \times 8 \mathrm{H}^{+}$(12). Trimethylsilylation of the methyl esters of the sialic acid in the isolated samples was performed as described by Kamerling et al. (9). The derivatives were analyzed by gas chromatography using a Packard Model 421 Becker gas chromatograph with a flame ionization detector, having a $6 \mathrm{ft} \times 4 \mathrm{~mm}$ internal diameter column packed with 3\% SE 30 
at a nitrogen carrier flow rate of $40 \mathrm{ml}$ per min. The temperature was programmed to rise from $180^{\circ}$ to $250^{\circ} \mathrm{C}$ at $5^{\circ} \mathrm{C}$ per min. Gas chromatography-mass spectrometry analyses were performed on a Dupont DP - 102 gas chromatography unit using a $5 \mathrm{ft} \times 2 \mathrm{~mm}$ internal diameter column packed with $3 \% \mathrm{OV}-101$ at a nitrogen carrier flow rate of $22 \mathrm{ml}$ per min with the temperature programmed to increase from $180^{\circ} \mathrm{C}$ to $280^{\circ} \mathrm{C}$ in $15 \mathrm{~min}(9)$.

To examine the synthesis of sialic acid from $\left[{ }^{3} \mathrm{H}\right] \mathrm{N}$-acetylmannosamine, skin fibroblasts were plated in $60 \mathrm{~mm}$ tissue culture dishes and incubated as previously described (13, 19). When confluent (usually 4 days), the media was removed, the cells washed with $2 \mathrm{ml}$ of sterile PBS and then incubated with $2 \mathrm{ml}$ of glucose-free MEM/Earle's Base buffered with $25 \mathrm{mM}$ Hepes and

Table 1. Lysosomal enzyme activities in sonicates of cultured fibroblasts of affected sibs and controls ${ }^{1}$

\begin{tabular}{lrrrrc}
\hline \multicolumn{5}{c}{ Enzyme } & \multicolumn{5}{c}{$\begin{array}{c}\text { Normal } \\
\text { mean }\end{array}$} & \pm 2 S.D. & $\begin{array}{c}\text { Normal } \\
\text { range }\end{array}$ \\
\hline PNP $N$-acetyl- $\beta$-glucos- & 10,785 & 10,823 & 4383 & \pm 1392 & $3071-5742$ \\
$\quad$ aminidase ${ }^{2}$ & & & & & \\
PNP $\alpha$-fucosidase & 130 & 72 & 35 & \pm 22 & $18-65$ \\
PNP $\beta$-galactosidase & 810 & 1040 & 581 & \pm 186 & $419-760$ \\
PNP $\alpha$-mannosidase & 229 & 469 & 101 & \pm 70 & $65-221$ \\
PNP $\beta$-mannosidase & 275 & 565 & 188 & \pm 138 & $102-238$ \\
Aspartylglucosamini- & 248 & 277 & 57 & \pm 42 & $27-131$ \\
$\quad$ dase & & & & & \\
4Mu-N-acetyl- $\beta$-glucos- & & & & & \\
aminidase & & & & & \\
Total & 7424 & 8428 & 3121 & \pm 1462 & $1966-4086$ \\
\%A & 51 & 31 & 54 & \pm 10 & $49-65$ \\
\hline
\end{tabular}

' Values expressed as nmoles of substrate cleaved per mg protein per $h$.

${ }^{2} 4 \mathrm{Mu}$, 4-methylumbelliferyl derivative and PNP, $p$-nitrophenyl derivative
$\mathrm{NaHCO}_{3}(\mathrm{KC}$ Biological Inc., Lenexa, KS) supplemented with heat inactivated, dialyzed fetal calf serum (13\%), glutamine $(1.7$ $\mu$ mole per $\mathrm{ml})$, glucose $(86 \mu \mathrm{g}$ per $\mathrm{ml})$ and $22.8 \mathrm{mCi}$ per mmole $\left[{ }^{3} \mathrm{H}\right] \mathrm{N}$-acetyl-D-mannosamine $(50 \mu \mathrm{Ci}$ per $\mathrm{ml})$. The cells were maintained at $37^{\circ} \mathrm{C}$ in a humidified atmosphere of $5 \% \mathrm{CO}_{2}-95 \%$ air.

After incubation, the media was removed, the cells were washed 6 times with $1 \mathrm{ml}$ quantities of PBS and harvested with trypsin $(13,19)$. The trypsinized cells were washed 3 times with $2 \mathrm{ml}$ quantities of PBS, suspended in $0.5 \mathrm{ml}$ water and sonicated for three 10 -sec periods. To $0.4 \mathrm{ml}$ cell sonicates, UDP- $N$-acetylglucosamine (200 nmoles), sialic acid ( 315 nmoles) and $\mathrm{N}$-acetylmannosamine (464 nmoles) were added, bringing the volume to 0.6 $\mathrm{ml}$. Cold $25 \%$ TCA $(0.4 \mathrm{ml})$ was added. After standing for $15 \mathrm{~min}$ on ice, the sample was centrifuged in the cold at $1084 \times \mathrm{g}$ for 10 min, and the supernatant was removed and saved. The precipitate was washed with $1 \mathrm{ml}$ of cold $10 \%$ TCA and the wash combined with the original TCA supernatant. The TCA insoluble precipitate was stored at $-60^{\circ} \mathrm{C}$ for later studies whereas the combined TCA soluble fraction was extracted with ether, neutralized with ammonium hydroxide, and stored as above.

The neutralized, soluble fractions were applied to ion-exchange columns $(0.5 \times 4 \mathrm{~cm})$ of Dowex $1 \times 8$ (200-400 mesh) in the formate form prepared according to the method of Hurlbert et al. (8). Columns were washed overnight with deionized water before sample application. Radioactive metabolites were eluted and collected in $0.5-\mathrm{ml}$ fractions at a rate of approximately $0.5 \mathrm{ml}$ per min according to a modification of the method of Akamatsu et al. (1) as follows: $7.5 \mathrm{ml}$ of sample + water; $7.5 \mathrm{ml}$ of $0.01 \mathrm{M}$ formic acid; $7.5 \mathrm{ml}$ of $1 \mathrm{M}$ formic acid; $7.5 \mathrm{ml}$ of $4.0 \mathrm{M}$ formic acid and $7.5 \mathrm{ml}$ of $4 \mathrm{M}$ formic acid/0.4 M ammonium formate. Fifty $\mu$ liters from each fraction was added to Liquiscint (National Diagnostics, Somerville, NJ) and the radioactivity determined with a Packard Model PL, PRIAS liquid-scintillation counter.

The TCA insoluble fractions obtained from the cell sonicates
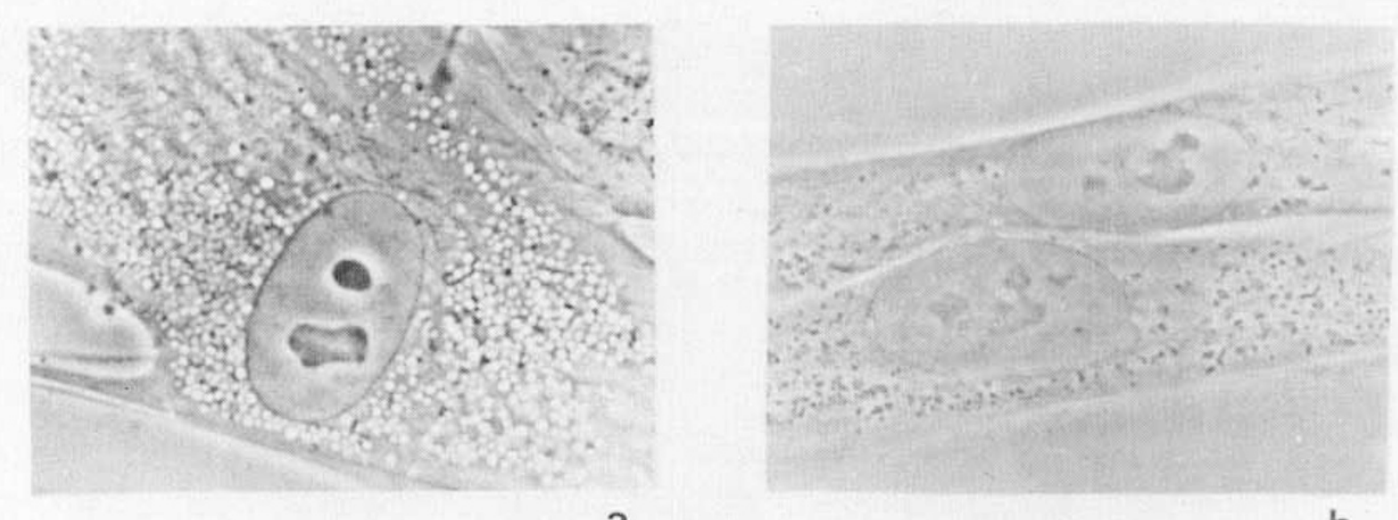

a
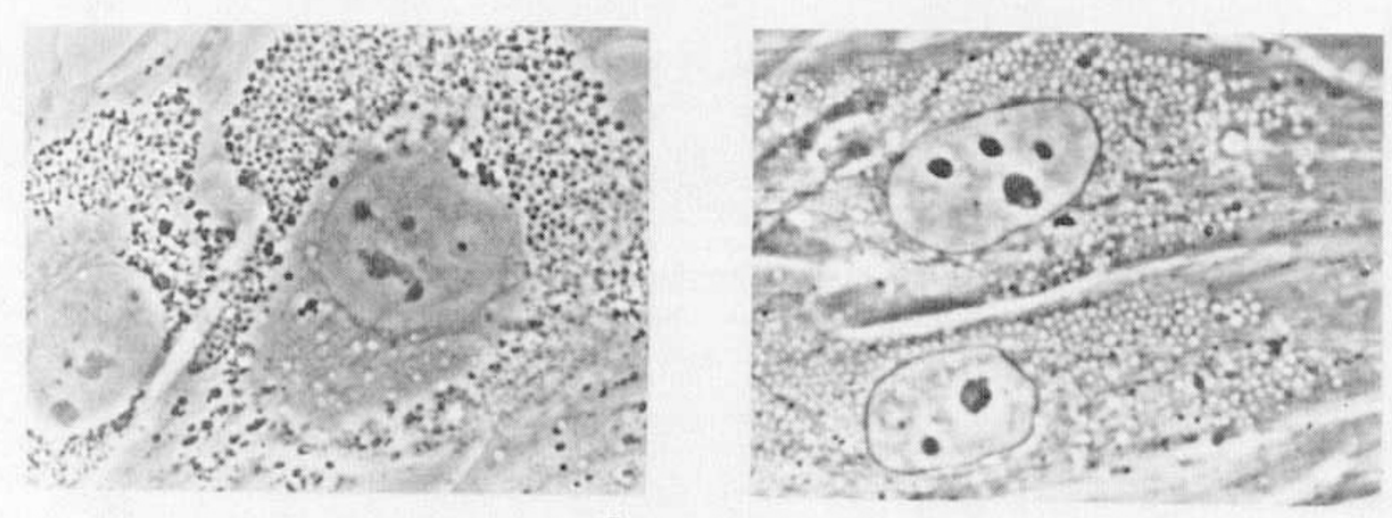

C

Fig. 1. Appearance of viable, cultured tibroblasts upon examination by phase contrast microscopy: (a) patient 1; (b) normal individual: (c) I-cell patient; and (d) sialidosis patient (lacking sialidase activity). 
were suspended in $0.5 \mathrm{ml}$ of $0.05 \mathrm{M}$ trifluoroacetic acid, heated at $80^{\circ} \mathrm{C}$ for $1 \mathrm{~h}$ and centrifuged at $1084 \times g$ for $10 \mathrm{~min}$. The supernatants were removed, the precipitates were washed twice with additional trifluoroacetic acid, the washes were combined with the supernatants and then dried. The dried residues were dissolved in water containing unlabeled sialic acid and $\mathrm{N}$-acetylmannosamine and analyzed on formate columns as outlined previously,

The lysosomal enzyme activities shown in Table 1 were measured according to the methods given in Thomas et al. (22) using crude sonicates prepared in the manner described above. Sialidase (neuraminidase) was measured in cell homogenates as described by Myers et al. (16) and by Thomas et al. (21).

Unstained, viable cells were examined by phase microscopy according to the method of Taylor et al. (22).

Thin layer chromatrography of the labeled sialic acid was carried out overnight on activated silica gel $G$ using butanol, acetic acid, and water $(50 / 25 / 25)$ according to the method of Humbel and Collart (7).

\section{RESULTS}

Skin fibroblast cultures were established from two sibs having neurologic and mental regression, coarse facies, hepatosplenomegaly and moderate signs of chondrodystrophy within the first year of life. Urine from these patients contained increased levels of sialic acid. A detailed description of these individuals will be reported elsewhere (23).

Upon examination by phase microscopy, viable (unstained and unfixed) fibroblasts cultured from each of the two affected sibs were found to have an abnormal appearance. The cells contained numerous, closely packed, small, round, vacuole-like structures distributed throughout most of the cytoplasm (Fig. la). In contrast, cells from normal individuals contained only a very small number of such structures (Fig. 1b). Although these structures were quite distinct and dissimilar to the inclusions seen in I-cell fibroblasts (Fig. lc), they did closely resemble the storage particles seen in certain sialidosis fibroblasts (Fig. 1d).

Examination of the ultrastructure of these cells by electron microscopy showed the abnormal structures to be simple, membrane-bound vacuoles of the type shown in Figure 2. Although most of these vacuoles appeared empty (presumably as a result of fixation), the remains of amorphous, fibrillogranular material suggestive of the storage of abnormal amounts of mucopolysaccharides and/or oligosaccharides was often detectable (Fig. 2).

Analysis of a variety of lysosomal enzymes known to be associated with inborn errors of lysosomal catabolism of these two classes of compounds failed to detect any deficiencies (Table 1). Moreover, sialidase activity, as measured with four different substrates, was 3-5 times that of control fibroblasts (Table 2). Finally, there was no evidence of a generalized maldistribution of any of these enzymes of the type seen in Mucolipidosis II and III. As shown in Table 1, however, several of these enzymes, in addition to sialidase, were elevated.

Sonicates of cultured fibroblasts from patients 1 and 2 however were found to contain approximately 4-7 times more thiobarbituric acid reactive material than control fibroblasts sonicates (Table 3). Because the material was not precipitated by $3.5 \%$ perchloric acid and reacted with thiobarbituric acid before mild acid hydrolysis, it appeared to be of low molecular weight and not glycosidically bound. The amount of additional thiobarbituric acid reactive material released in $1 \mathrm{~h}$ by $0.1 \mathrm{~N} \mathrm{H}_{2} \mathrm{SO}_{4}$ at $80^{\circ} \mathrm{C}$ was just above the upper limit of the normal control (Table 3). Upon chromatography on a Dowex column (acetate form), the reactive

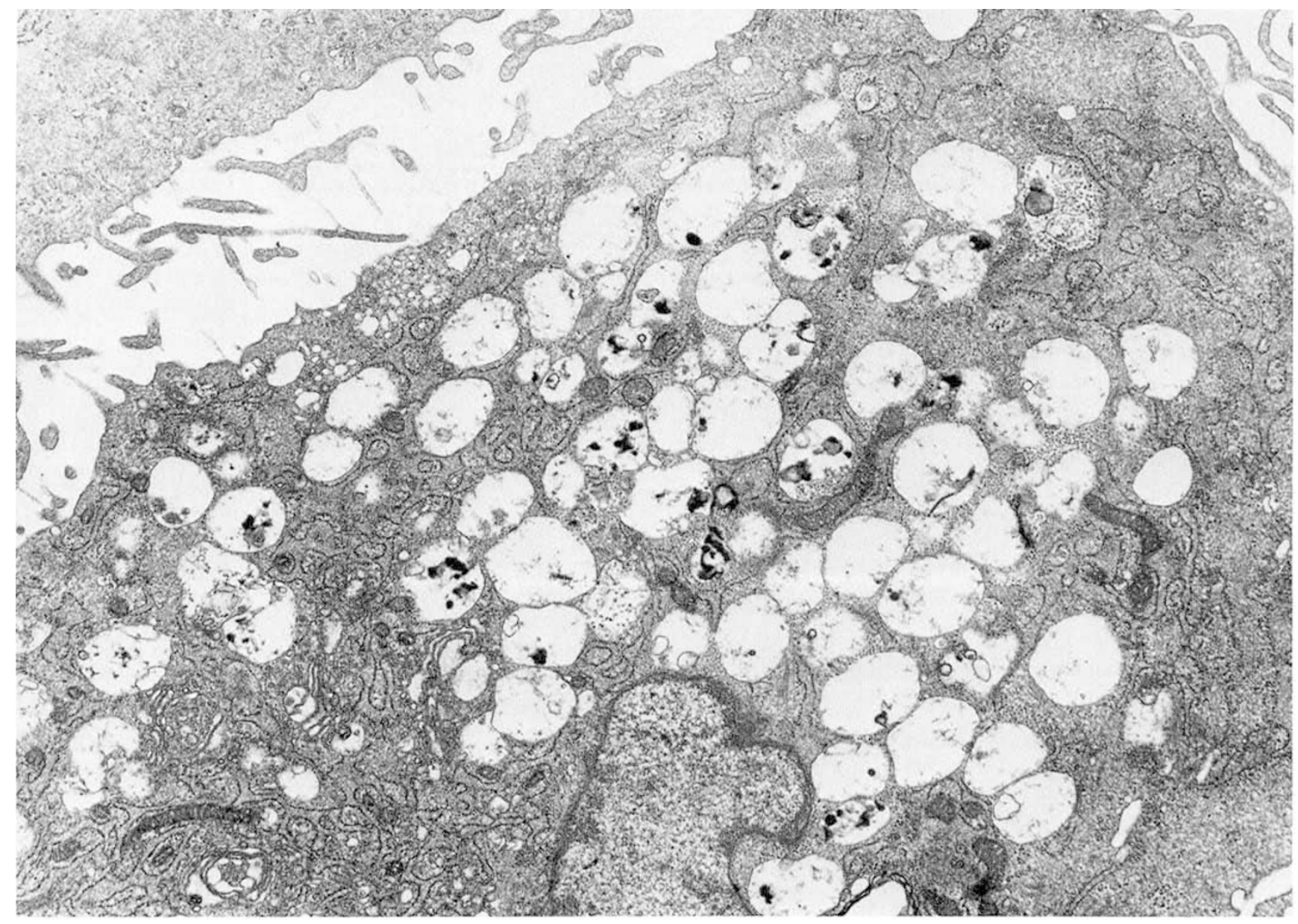

Fig. 2. Appearance of cultured fibroblast cells of patient 1 upon examination by electron microscopy. 
Table 2. Sialidase activity in ruptured fibroblasts of affected sibs and controls

\begin{tabular}{|c|c|c|c|c|}
\hline \multirow[b]{2}{*}{ Substrate } & \multirow[b]{2}{*}{ Sib I } & \multirow[b]{2}{*}{ Sib 2} & \multicolumn{2}{|c|}{ Controls } \\
\hline & & & Average & Range \\
\hline Fetuin & 109 & N.D. ${ }^{3}$ & 27 & $16-40$ \\
\hline$N$-Acetylneuraminyllactose ${ }^{1}$ & 496 & N.D. & 101 & $71-142$ \\
\hline $\begin{array}{l}\left.\text { 2-( } 3^{\prime} \text { methoxyphenyl }\right)-\mathrm{N} \text {-ace- } \\
\text { tyl-neuraminic acid }{ }^{1}\end{array}$ & 443 & N.D. & 153 & $105-226$ \\
\hline $\begin{array}{l}\text { 4-Methylumbelliferyl- } N \text {-ace- } \\
\text { tyl-neuraminic acid }\end{array}$ & 242 & 367 & 51 & $28-66$ \\
\hline
\end{tabular}

\footnotetext{
' nmoles cleaved per mg protein per $6 \mathrm{~h}$.

${ }^{2}$ nmoles cleaved per mg protein per $\mathbf{l} \mathbf{h}$.

${ }^{3}$ N.D., not determined.
}

Table 3. Thiobarbituric acid reactive material (sialic acid) present in cultured fibroblasts

\begin{tabular}{lccc} 
& \multicolumn{2}{c}{ Free $^{2}$} & \\
\cline { 2 - 3 } & Sonicate & Isolated $^{4}$ & Bound $^{3}$ \\
\hline Sib. 1 & 57.3 & 39.8 & 24.8 \\
Sib. 2 & 34.5 & N.D. & 21.5 \\
Controls & & & \\
Controls & & & \\
$\quad$ Average & 8.2 & 1.5 & 18.3 \\
$\quad$ Range & $2.7-18.1$ & $1.2-2.1$ & $11.3-23.2$ \\
\hline
\end{tabular}

' nmoles of "thiobarbituric acid material" per mg protein using $\mathrm{N}$ acetylneuraminic acid as standard.

${ }^{2}$ Reactive with thiobarbituric acid before acid hydrolysis.

${ }^{3}$ Determined by subtracting unbound sialic acid values from total sialic acid values. Total sialic acid equals unbound sialic acid plus sialic acid released by hydrolysis with $0.1 \mathrm{~N} \mathrm{H}_{2} \mathrm{SO}_{4}$ at $80^{\circ}$ in $60 \mathrm{~min}$.

${ }^{4}$ Eluted from Dowex column (acetate form) by $10 \%$ acetic acid.

${ }^{5}$ N.D., not determined.

material was eluted with $10 \%$ acetic acid in a fashion identical to that of authentic sialic acid. In contrast, deoxyribose, which also reacts with thiobarbituric acid is not retained by this Dowex column.

The reactive material eluted from the Dowex column with $10 \%$ acetic acid was further characterized by gas liquid chromatography and mass spectrometry. The trimethylsilyl derivative of the methyl ester of this material, showed one major component with a retention time identical to that of the trimethylsilylated methyl ester of authentic sialic acid. When examined by mass spectrometry, the isolated compound displayed the same fragmentation pattern (Fig. 3 ) as the pure sialic acid standard (Fig. 4).

As the acidic conditions of the preceding procedures would cleave CMP-sialic acid, the values given in Table 3 are a measure of not only free sialic acid but also CMP-sialic acid. An estimate of the contribution of CMP-sialic acid to these values was obtained by incubating cell sonicates with sodium borohydride to destroy any free sialic acid. After oxidation of the excess borohydride, the CMP-sialic acid was hydrolyzed and measured by the thiobarbituric acid procedure. When treated in this manner the CMP-sialic acid levels of the patients' fibroblasts were similar to those of the control fibroblasts ( 3.1 versus 3.9 nmoles per mg protein).

Additional evidence for an abnormality in sialic acid synthesis and/or utilization was obtained from an examination of sialic acid formation from $N$-acetylmannosamine. $N-\left[{ }^{3} \mathrm{H}\right]$-acetylmannosamine was added to fibroblasts cultured in Hepes buffered, low glucose media. After $6,12,24,48$, and $72 \mathrm{~h}$, cells were washed, harvested, sonicated, and treated with 10\% TCA as outlined in the "Materials and Methods" section. After ether extraction, the acid soluble fractions were neutralized and applied to $0.5 \times 4 \mathrm{~cm}$ columns of Dowex $1 \times 8$ (200-400 mesh, formate form). After a wash step, the adsorbed radioactivity was eluted stepwise with increasing concentrations of formic acid. At least seven distinct peaks of radioactivity were obtained. A major peak of radioactivity eluted by $1 \mathrm{M}$ formic acid was found in the same fraction as unlabeled NANA added as an internal standard before the TCA precipitation of the cell sonicates. Analysis of this peak from the patients' fibroblasts by thin layer chromatography on silica gel $G$ revealed a single radioactive peak with a $R_{f}$ value identical to sialic acid. Incubation of a second aliquot of this material in the presence of aldolase, that cleaves sialic acid to $N$-acetylmannosimine and pyruvate, resulted in the formation of a labeled compound that was not retained on Dowex 1 formate columns. From these data it was concluded that this radioactive material was sialic acid formed from the added $N$-acetylmannosamine precursor.

As illustrated in Figure $5 \mathrm{a}$, the level of radioactivity in the NANA peak from the acid soluble fraction of the control fibroblasts did not increase after $12 \mathrm{~h}$ of incubation in the presence of $n-\left[{ }^{3} \mathrm{H}\right]$-acetylmannosamine. In contrast, fibroblasts from the patients continued to accumulate radioactivity in the sialic acid fraction throughout the duration of the experiment (Fig. 5a). By $72 \mathrm{~h}$ the amount of radioactivity in the sialic acid from the patient's fibroblast was more than 7 times that of the control fibroblasts (Fig. 5a).

The radioactivity in the TCA-insoluble fraction obtained during the same studies was analyzed in a similar fashion after hydrolysis with $0.05 \mathrm{M}$ trifluoroacetic acid as outlined in the methods section. Greater than $90 \%$ of the radioactivity in this fraction had the chromatographic properties of authentic sialic acid. In contrast to the free (acid soluble) radioactive sialic acid, the radioactivity of the TCA insoluble sialic acid continued to increase throughout the duration of the $72 \mathrm{~h}$ experiment in the control as well as the patient (Fig. 5b). As shown in Figure 5b, these cell strains did not differ significantly in the amount or rate of incorporation of labeled sialic acid into this fraction.

\section{DISCUSSION}

The morphologic and biochemical findings reported in this paper demonstrate the presence of abnormal storage in these fibroblasts. Phase and electron microscopy studies show that

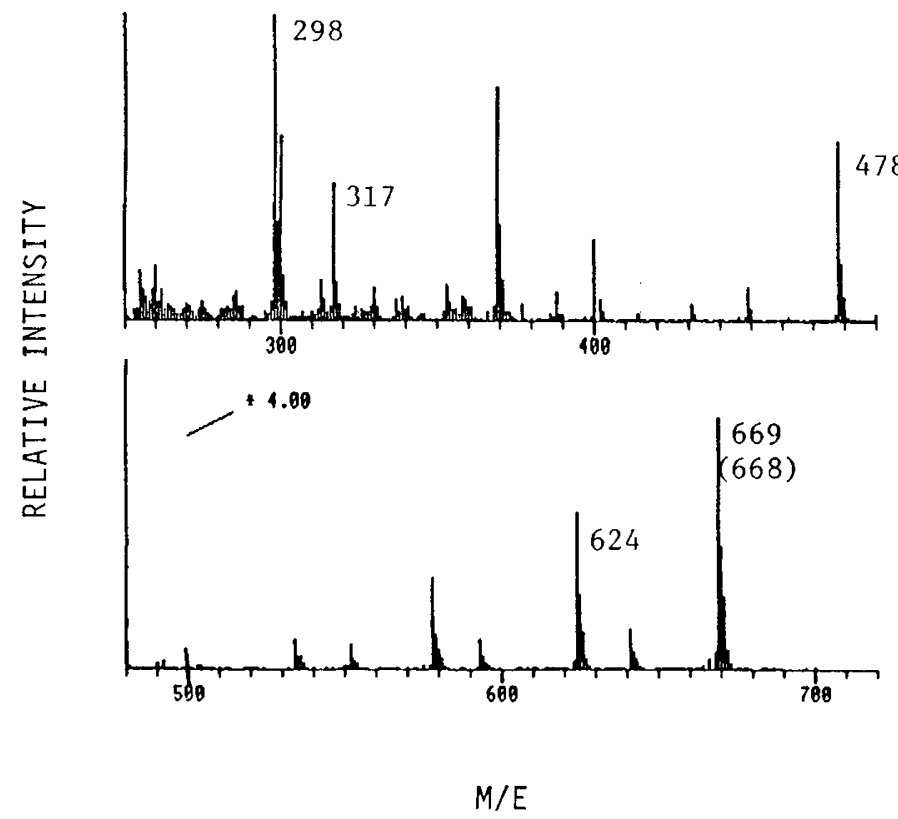

Fig. 3. Mass spectra of trimethylsilyl derivative of material isolated from fibroblasts of patient. Note: high pressure in the instrument source in some runs caused $\mathrm{m} / \mathrm{e}$ values to appear $\mathbf{l}$ amv high in the spectra. 


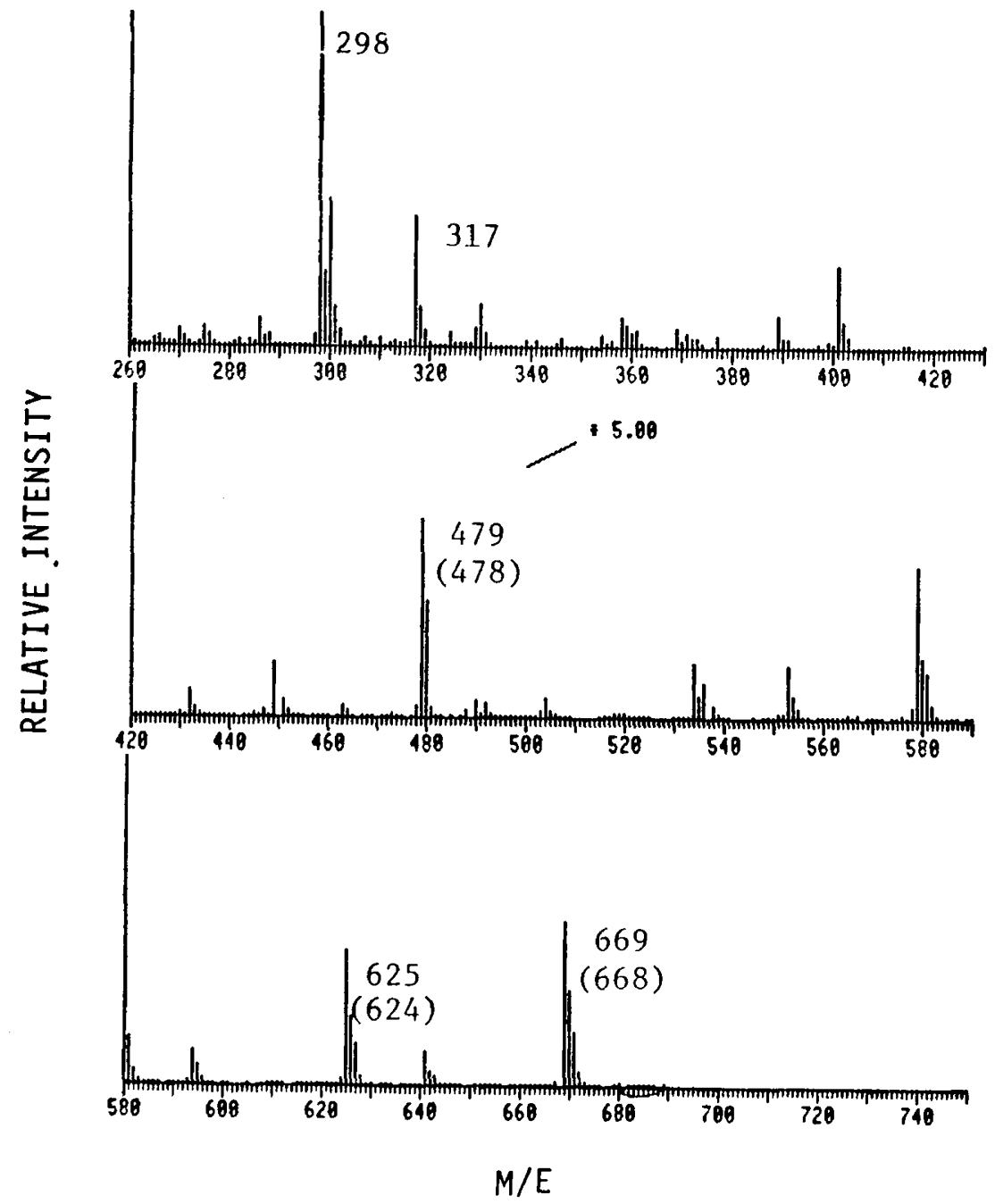

Fig. 4. Mass spectra of trimethylsilyl derivative of $\mathrm{N}$-acetyl neuraminic acid.

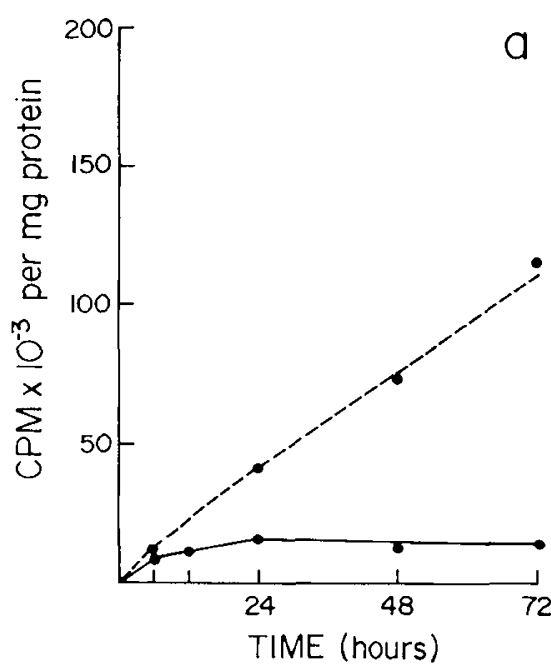

Fig. 5. Radioactivity in sialic acid peak of patient (---) and control trichloracetic acid soluble and (b) trichloracetic acid insoluble.

increased storage occurs in distinct subcellular organelles, most likely distended lysosomes (Fig. 1). Although the fibrillogranular appearance of the stored material is suggestive of mucopolysaccharides, oligosaccharides and/or glycoproteins, no evidence for increased levels of these compounds was found.

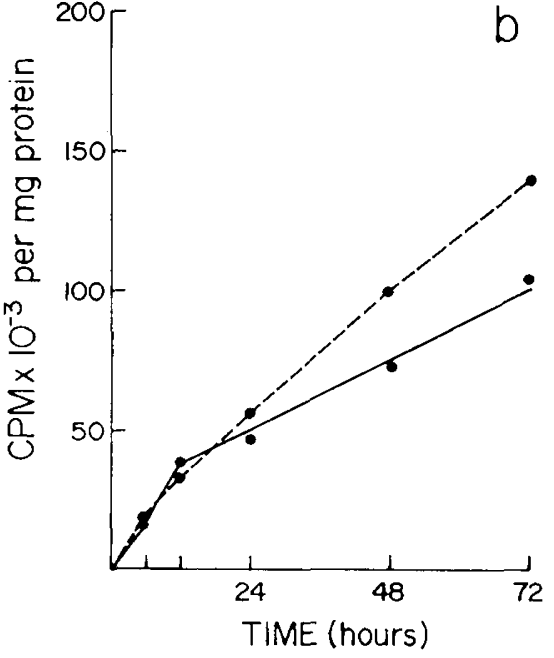

) fibroblasts after incubation in $N-\left[\mathrm{H}^{3}\right]$ acetyl-D-mannosamine: (a)

Instead, direct biochemical analysis indicates that there is a marked accumulation ( $26 \times \mathrm{N})$ of free sialic acid in these cells (Table 3). Although it is likely that this is the material seen by electron microscopy, direct proof regarding this point is lacking. It is in keeping, however, with the observation by Tondeur et al. 
(23) that urine from these same patients contains increased levels of free sialic acid.

Labeling experiments utilizing $\left[{ }^{3} \mathrm{H}\right] N$-acetylmannosamine resulted in the accumulation of increased amounts of labeled free sialic acid in the patients' fibroblasts (Fig. 5). This finding suggests that the increased levels of sialic acid probably do not arise from preformed sialic acid from extracellular sources. It also suggests that the alteration does not result from a lack of feedback control at an early step (before the formation of $\mathrm{N}$-acetylmannosamine) in sialic acid synthesis. Finally, the presence of normal amounts of labeled, bound sialic acid in the acid insoluble components of the cells argues against a gross defect in the ability of these cells to transfer sialic acid via CMP-sialic acid to cellular glycoproteins. Furthermore, it provides additional evidence that these patients do not suffer from a defect in sialo-glycoprotein metabolism as is the case with cells lacking sialidase. Alternate metabolic pathways, controls, and transport systems that might affect sialic acid concentrations are currently being examined.

We are aware of two additional patients having similar findings. Stevenson et al. (18) noted abnormal phase microscopy findings, as well as thiobarbituric acid positive material in the fibroblasts of a male with similar clinical findings. Horwitz et al. (6) have also provided, in an abstract, evidence for alterations in the free sialic acid concentration in fibroblasts of a male with fetal hydrops, hepatomegaly, and abdominal ascites. Recently Hancock et al. (5) have also demonstrated excessive amounts of free sialic acid in the brain, liver, and kidney of this same patient. There is, in addition, a report of a single patient who excretes massive amounts of sialic acid but appears to have a different clinical disorder (15). Finally, a large number of adult patients with a milder clinical disorder have recently been shown to excrete unbound sialic acid $(3,17)$.

Inasmuch as the biochemical, genetic, and clinical relationships among these patients remain unclear, it does suggest that abnormalities in sialic acid metabolism or transport are responsible for another, as yet poorly defined, group of inherited, human disorders.

\section{REFERENCES AND NOTES}

1. Akamatsu, N., Nakajima, H., and Miyata, S.: Glucosamine metabolism in regenerating rat liver. Biochem. J., 158: 589 (1976).

2. Aminoff, D.: Methods for the quantitative estimation of $\mathrm{N}$-acetylneuraminic acid and their application to hydrolysates of sialomucoids. Biochem. J., 81: 384 (1961).

3. Aula, P., Autio, S., Raivio, K. O., Rapola, J. Thodén, C.-J., Koskela, S.-L., and Yamashina, I.: 'Salla disease' A new lysosomal storage disorder. Arch. Neurol. 36: $88(1979)$.

4. Aylsworth, A. S., Thomas, G. H., Hood, J. L., Malouf, N. and Libert, J.: A severe infantile sialidosis: clinical, biochemical and microscopic features. J. Pediatr.. 96: $662(1980)$.

5. Hancock, L. W., Thaler, M. M., Horwitz, A. L., and Dawson, G.: Generalized $\mathrm{N}$-acetylneuraminic acid storage disease: Quantitation and identification of the

Copyright (c) 1983 International Pediatric Research Foundation, Inc. $0031-2998 / 83 / 1705-0307 \$ 02.00 / 0$ monosaccharide accumulating in brain and other tissues. J. Neurochem., 38 : 803 (1982)

6. Horwitz, A. L., Hancock, L., Dawson, G. and Thaler, M. M.: Abs. Generalized sialic acid storage disease. Pediatr. Res., 15: 563 (1981)

7. Humbel, R. and Collart, M.: Oligosaccharides in urine of patients with glycoprotein storage diseases. Clin. Chim. Acta, 60: 143 (1975).

8. Hurlbert, R. B., Schmitz, H., Brumm, A. F., and Potter, V. R.: Nucleotide metabolism. II. Chromatographic separation of acid-soluble nucleotides. J. Biol. Chem., 209: 23 (1954).

9. Kamerling, J. P., Vliegen Thart, J. F. G., Versluis, C., and Sahauer, R.: Identification of $\mathrm{O}$-acetylated $\mathrm{N}$-acylneuraminic acids by mass spectrometry. Carbohydr. Res., 41: 7 (1975).

10. Kean, E. L. and Roseman, S.: CMP-Sialic acid synthetase (cytidine-5'-monophosphosialic acid synthetase). Methods in Enzymology, 8: 208 (1966).

11. Krantz, M. and Lee, Y. C.: A sensitive autoanalytical method for sialic acids. Anal. Biochem., 63: 464 (1975).

12. Kuhn, R., Lutz, P., and MacDonald, D.: Synthesis anomerer sialinsaure-methylketoside. Chem. Ber., 99: 611 (1966).

13. Lie, K. K., Thomas, G. H., Taylor, H. A., and Sensenbrenner, J. A.: Analysis of $N$-acetyl- $\beta$-D-glucosaminidase in mucolipidosis II (I-cell disease). Clin. Chim. Acta., 45: 243 (1973)

14. Lowden, J. A. and O'Brien, J. S.: Sialidosis: A review of human neuraminidase deficiency. Am. J. Hum. Genet., 31: 1 (1979).

15. Montreuil, J., Biserte, G., Strecker, G., Spik, G., Fontaine, G., and Farriaux J.P.: Description d'un nouveau type du méliturie: La sialurie. Clin. Chim. Acta, 21: 61 (1968)

16. Myers, R. W., Lee, R. T., Lee, Y. C., Thomas, G. H., Reynolds, L. W., and Uchida, Y.: The synthesis of 4-methylumbelliferyl $\alpha$-ketoside of $\mathrm{N}$-acetylneuraminic acid and its use in a fluorometric assay for neuraminidase. Anal. Biochem., 101: 166 (1980).

17. Renlund, M., Chester, M. A., Lundblad, A., Aula, P., Raivio, K. O., Autio, S., and Koskela, S.-L.: Increased urinary excretion of free $\mathrm{N}$-acetylneuraminic acid in thirteen patients with Salla disease. FEBS Europ. J. Biochem., 101: 245 (1979).

18. Stevenson, R. E., Taylor, H. A and Schroer, R. J. Sialuria-clinical and laboratory features of a severe infantile form. Proc. of the Greenwood Genetics Center, l: 73 (1982).

19. Taylor, H. A., Thomas, G. H., Miller, C. S., Kelly T. E. and Siggers, D.: Mucolipidosis III (pseudo-Hurler polydystrophy): cytological and ultrastructural observations of cultured fibroblast cells. Clin. Genet., 4: 388 (1973).

20. Thomas, G. H., Goldberg, M. F., Miller, C. S., and Reynolds, L. W.: Neuraminidase deficiency in the original patient with the Goldberg syndrome. Clin Genet., 16: 323 (1979).

21. Thomas, G. H., Reynolds, L. W., and Miller, C. S.: Characterization of neuraminidase activity of cultured human fibroblasts. Biochim. Biophys. Acta, 568 : 39 (1979).

22. Thomas, G. H., Tipton, R. E., Ch'ien, L. T., Reynolds, L. W., and Miller, C. S.: Sialidase ( $\alpha$ - $N$-acetylneuraminidase) deficiency: the enzyme defect in an adult with macular cherry-red spots and myoclonus without dementia. Clin. Genet., 13: 369 (1978).

23. Tondeur, M., Libert, J., Vamos, E., Van Hoof, F., Thomas, G. H., and Strecker, G.: Infantile form of sialic acid storage disorder: clinical, ultrastructural, and biochemical studies in two siblings. European J. Ped., 139: 142 (1982).

24. Uchida, Y., Tsukada, Y., and Sugimori, T.: Distribution of neuramiridase in Arthrobacter and its purification by affinity chromatography. J. Biochem., 82: 1425 (1977).

25. Requests for reprints should be addressed to: George H. Thomas, Ph.D., The John F. Kennedy Institute, 707 N. Broadway, Baltimore, MD 21205 (USA).

26. This research was supported by NIH grant HD-10981.

27. The authors wish to thank Dr. Michel Tondeur for referring this patient to us.

28. Received for publication April 27, 1982.

29. Accepted for publication August $9,1982$. 